\title{
Mental health and foster carer training
}

\author{
H Minnis, A J Pelosi, M Knapp, J Dunn
}

\begin{abstract}
Aims-To evaluate the impact of training foster carers on children's emotional and behavioural functioning. Methods-In a randomised controlled trial in 17 Scottish local council areas, with immediate and nine month follow up, 182 children and their foster families were randomly allocated to either standard services alone or standard services plus extra training for foster carers on communication and attachment. Main outcome measures were child psychopathology, attachment disorder, self esteem, and cost of foster care.

Results-Over $60 \%$ of children had measurable psychopathology at baseline. The training was perceived as beneficial by participants. Scores for parent reported psychopathology and attachment disorders decreased by around $5 \%$, self esteem increased by $2 \%$, and costs by $22 \%$ in the intervention group. Results were nonsignificant.

Conclusions-Despite being well received by foster carers, the training was not sufficient to make a useful impact on the high level of psychopathology. This group may warrant more intensive interventions.

(Arch Dis Child 2001;84:302-306)
\end{abstract}

Keywords: foster care; training; mental health

In Scotland nearly $3000^{1}$ and in England and Wales over 30000 children are in foster care. ${ }^{2}$ This is a vulnerable group. ${ }^{3}$ Fostering was once dominated by placement of "non-problematic" children; nowadays the threshold for placement is higher, ${ }^{4}$ and a prevalence of clinically significant psychopathology of $57 \%$ has been estimated. ${ }^{5-7}$

Randomised trials of "specialised" foster care including enhanced pay and training for carers plus regular mental health service contact involving family therapy, individual therapy, and frequent telephone consultation, have shown improvements in children's psychopathology. All participants had severe problems, ${ }^{8}$ and such schemes are clearly expensive. ${ }^{910}$ In mainstream services, nonrandomised studies have suggested benefits from training foster carers. ${ }^{11-13} \mathrm{~A}$ brief, affordable intervention with an impact on these children's problems would be of major importance.

The role of attachment problems as a risk factor for later psychopathology is well established, ${ }^{14-16}$ and there is a complex relation between communication with care givers and attachment. ${ }^{17-19}$ Attachment in foster care, where children have inevitably suffered separation and loss, has not been studied. Fostered children often have no one to confide in, ${ }^{20} 21$ and both carers and children find communication about painful issues difficult. ${ }^{20} 22$

We hypothesised that a training programme for foster carers, focusing on communication skills and attachment, would have a beneficial effect on the emotional and behavioural functioning of "looked after" children. Because such training should be affordable and widely applicable by local councils, the programme was restricted to three full days.

\section{Subjects and methods}

The study ran from May 1996 to December 1998. Written consent was obtained from foster carers, birth parents, and older children. Verbal consent of younger children was obtained in the presence of the foster carer. Ethical approval of Yorkhill NHS Trust and participating social work departments was obtained.

\section{PARTICIPANTS}

All foster carers from 17 Scottish council areas were offered entry to the study if caring for children aged 5 to 16 who were likely to be in placement for a further year. Final numbers of recruited subjects depended on the following factors: (1) permission of senior social work management in each council area to allow the trial to proceed; (2) agreement of social workers to allow children on their caseloads to participate in the study; (3) consent to participate from birth parents, foster carers, and the children.

PROTOCOL

The training, developed in a qualitative pilot study, ${ }^{23}$ was based on Communicating with children: helping children in distress, a Save the Children manual used internationally. ${ }^{24}$ It was delivered by an experienced social worker/ trainer. Families were randomly allocated to standard services alone or to extra training. Training sessions ran for six hours per day, the first two days running consecutively with a follow up day one week later. Didactic material was followed by group discussion utilising carers' own experience. At the end of days 1 and 2, tasks were set for discussion at the beginning of the next training day. Those in both the control and intervention groups received whatever training and support was offered by social work departments during the course of the study.

OUTCOME MEASURES

Before and nine months after the training programme, carers, teachers, and children completed the Strengths and Difficulties Question- 


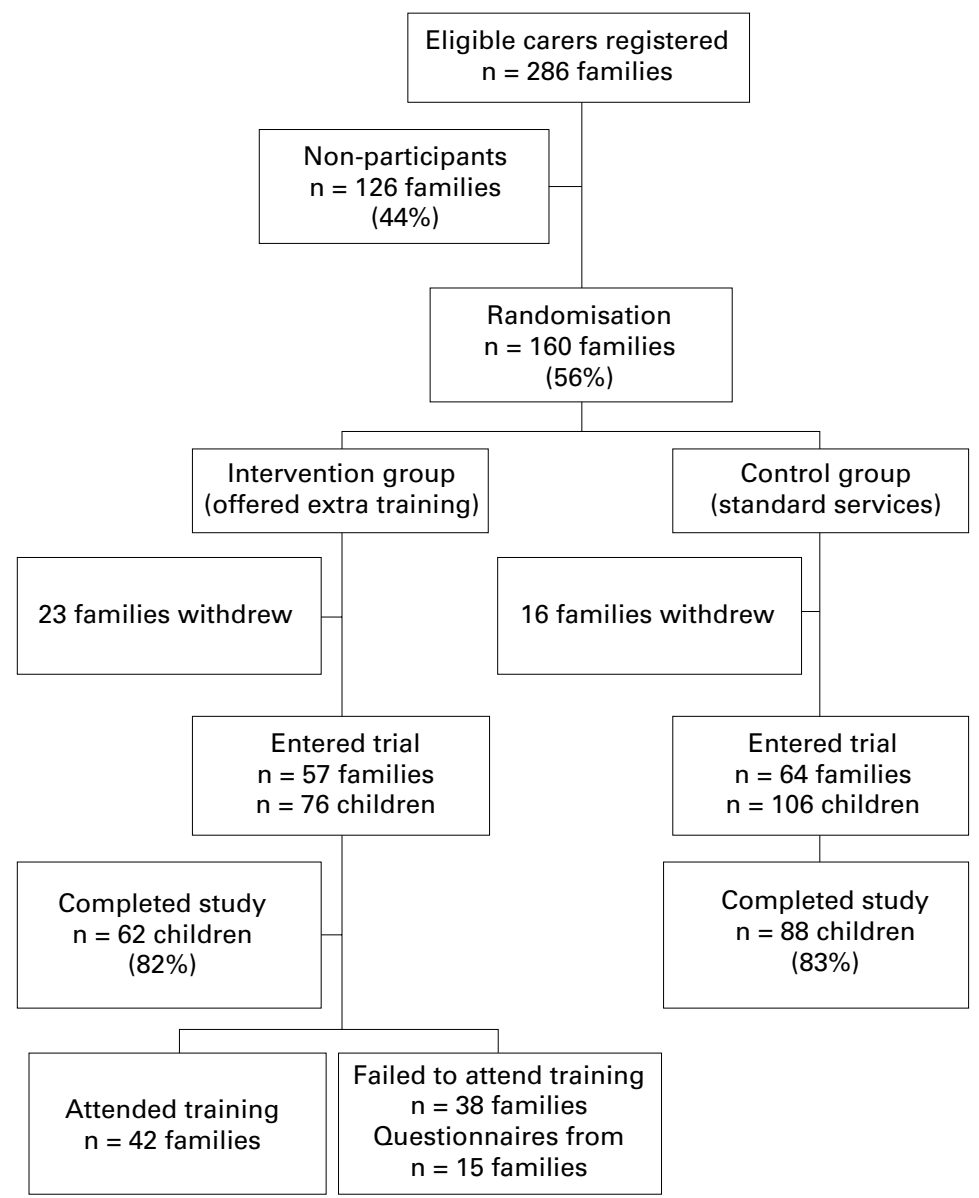

Figure 1 Flow chart showing progress of carers and children throughout trial.

naire (SDQ). This 25 item screening instrument for child psychopathology gives an overall score (range 0 to 40 ) and subscale scores (range 0 to 10) for hyperactivity, conduct problems, emotional problems, peer problems, and prosocial (caring, helpful) behaviour. ${ }^{25}$ Children completed the eight item Modified Rosenberg Self-esteem Scale (MRS), before and nine months after the training. ${ }^{26}$ The SDQ and MRS were administered on a laptop computer during home visits. Before, immediately after, and nine months after the training, foster carers completed the Reactive Attachment Disorder Scale (RAD). This 17 item questionnaire for attachment disorders gives an overall score ranging from 0 to 51 . It has good internal consistency with a Cronbach's alpha of 0.70 , test-retest reliability (repeat questionnaire completion after approximately one month) of 0.77 , and interrater reliability (between parents) of $0.81 .^{27}$ Before and nine months after the training, foster carers completed the Costs of Foster Care Questionnaire, developed for the study, which asks about contact with social workers, doctors, psychology, the criminal justice system, other foster carers, and school. Costs were calculated using Unit Costs of Health and Social $\mathrm{Care}^{28}$ and by contacting individual workers. The cost of training was averaged over all those randomised to the intervention group. Background information about the children and their placements was given by social workers.
Carers participating in the training completed a six item evaluation questionnaire designed for the study.

SAMPLE SIZE CONSIDERATIONS

A study such as this has not been attempted previously. Epidemiological surveys using the SDQ have shown differences in scores of greater than $15 \%$ among children in stepfamily, single parent, and non-stepfamily settings. ${ }^{29}$ In deciding on the size of this trial we considered that it should have sufficient power to show a difference in mean scores of $15 \%$ between the intervention and control groups, as a score of this magnitude would be of public health importance. Pilot work suggested a baseline mean score on the parental SDQ of 19.4. Using the same standard deviation as Dunn et al (5.9), ${ }^{29} 60$ children per group were required for a power of $90 \%$ at the $5 \%$ level. The design effect (deff) correction with an average cluster size of 1.7 and an estimated intracluster correlation of 0.1 , resulted in a sample size of 64 children per group. ${ }^{30}$ Because of the uncertainties inherent in both the recruitment steps and the power calculations, and to allow for attrition during follow up, we planned to recruit 75 children in each group.

RANDOMISATION AND BLINDING

Families were randomised, after consent, using random permuted blocks of block size $12 .^{31}$ The trial was single blind, and stringent measures were taken to maintain this. The randomisation list and identifying information such as receipts were handled only by the study secretary. Participants were reminded about blindness in all letters and at the beginning of phone or face to face contacts. Double blinding was felt to be unfeasible and unethical. A truly "placebo" programme would have wasted participants' time and would be impossible to construct, as simply meeting up with others might benefit carers.

\section{STATISTICAL ANALYSIS}

To estimate differences between the groups, we measured the mean differences, 95\% confidence intervals, and $\mathrm{p}$ values. We used analysis of covariance to measure the mean differences between the groups, taking into account baseline scores and variables which had an effect on training outcome and were imbalanced after randomisation. We used an "intention to treat" analysis to compare the intervention and control groups regardless of whether the family attended the training. Data are presented from female foster carers, except where male carers were single heads of families $(n=6)$. Although families were randomised, children's data were analysed, and the Huber correction $^{32}$ was used to correct for any correlation between children living in the same family and to allow for the skewed distributions found in the analysis of costs to be used legitimately in the regression. We used computer software STATA version 4.0. 
Table 1 Baseline details of 121 families with 182 children participating in the study

\begin{tabular}{|c|c|c|}
\hline & $\begin{array}{l}\text { Control group } \\
\text { ( } 64 \text { families; } 106 \\
\text { children) }\end{array}$ & $\begin{array}{l}\text { Intervention group } \\
\text { (57 families; } 76 \\
\text { children) }\end{array}$ \\
\hline Mean (SD) age of child (y) & $11.6(3.27)$ & $10.9(3.1)$ \\
\hline $\begin{array}{l}\text { Median (range) number of children previously } \\
\text { placed in foster home }\end{array}$ & $14(1,140)$ & $18(1,91)$ \\
\hline $\begin{array}{l}\text { Mean (SD) length of time foster carers have } \\
\text { known children (mth) }\end{array}$ & $32(33)$ & $29(26)$ \\
\hline $\begin{array}{l}\text { Median (range) deprivation category of foster } \\
\text { carers }\end{array}$ & $4(1,7)$ & $4(1,7)$ \\
\hline Mean (SD) foster mother's age & $46(7.8)$ & $45(8.8)$ \\
\hline Mean (SD) foster father's age & $48(7.3)$ & $46(10)$ \\
\hline \multicolumn{3}{|l|}{ Sex of fostered child } \\
\hline Male & $56(59)$ & $58(44)$ \\
\hline Female & $44(47)$ & $42(32)$ \\
\hline $\begin{array}{l}\text { Children classed as psychiatric "cases" on the } \\
\text { foster carer report SDQ }\end{array}$ & $58(59)$ & $74(56)$ \\
\hline Children previously abused & $87(76)$ & $80(46)$ \\
\hline Children previously neglected & $72(61)$ & $76(42)$ \\
\hline Children previously abused or neglected & $93(79)$ & $89(49)$ \\
\hline Children previously in residential care & $27(23)$ & $27(15)$ \\
\hline Children previously in foster care & $69(59)$ & $78(43)$ \\
\hline Children with a physical disability & $5(4)$ & $11(6)$ \\
\hline Children with a learning disability & $26(22)$ & $27(15)$ \\
\hline Children with no contact with birth parents & $20(17)$ & $24(13)$ \\
\hline
\end{tabular}

Values are percentages (numbers) unless stated otherwise. Numbers vary due to missing data.

\section{Results}

SUBJECTS

Figure 1 shows details of participant flow and follow up. We recruited 160 families, but some withdrew after randomisation; slightly more from the intervention group. This left a final sample of 121 families with 182 children. Fifteen families randomised to the training did not attend. Table 1 shows the baseline characteristics of participants. Analyses were adjusted to account for any imbalances after randomisation. The postal response rate immediately post-training was only $54 \%$ (hence the lower numbers in table 2), so for the nine month follow up, the majority of questionnaires were completed by foster carers and children during a home visit. Eighty two per cent completed the study and were followed up for nine months after the training. The only statistically significant difference between "completers" and "non-completers" was that the latter were younger (mean age $43 v 46$ years; $\mathrm{p}=0.04$ ).

Deprivation categories and the rate of breakdown of placements were known for those who were offered entry to the trial but did not participate. The modal deprivation category was the same (4) for participants and nonparticipants; the number of families experiencing a placement breakdown was $24(19 \%)$ for participants and $25(21 \%)$ for nonparticipants, a non-significant difference $(\mathrm{p}=0.6)$.

\section{CHARACTERISTICS OF THE CHILDREN}

As table 1 shows, $93 \%$ of children had suffered previous abuse or neglect and over $60 \%$ had some degree of psychopathology.

BASELINE TRAINING OFFERED BY COUNCILS Excluding the intervention, the mean hours of training attended by carers during the study was six (range 0 to 42 ); $48 \%$ had attended none. Of those randomised to the intervention group, $48 \%$ did not attend the extra training.

PERCEPTION OF THE TRAINING

The mean score for the six questions comprising the Perceived Benefit Scale was 2.5 (SD $0.6 ; \mathrm{n}=48$ ) with a maximum of 3 -that is, training participants on average perceived substantial benefit from it. They enjoyed the training, and felt they were better carers since the training, that the child they were looking after was better behaved, and that their relationship had improved.

OUTCOME IMMEDIATELY AFTER TRAINING

Table 2 shows outcomes immediately posttraining. We compared children whose families were invited to attend the extra training with

Table 2 Outcomes immediately after training for 100 children, using the Huber correction

\begin{tabular}{llll}
\hline & \multicolumn{1}{l}{ Study group } & & Mean difference due to training \\
\cline { 2 - 4 } Variable & Intervention group & Control group & (95\% CI)* \\
\hline $\begin{array}{l}\text { Mean (SD) score on foster carer report } \\
\begin{array}{l}\text { Reactive Attachment Disorder Scale after } \\
\text { training }\end{array}\end{array}$ & $21(8)$ & $17(9)$ & $0.53(-1.6,2.6)$ \\
\hline
\end{tabular}

*Adjusted for pretraining scores, the number of children previously looked after by the foster carers, and the sex and age of the child.

Table 3 Outcomes nine months after training for 151 children, using the Huber correction and Bootstrapping for costs data

\begin{tabular}{|c|c|c|c|c|}
\hline \multirow[b]{2}{*}{ Variable } & \multicolumn{2}{|l|}{ Study group } & \multirow{2}{*}{$\begin{array}{l}\text { Mean difference due to training } \\
(95 \% \mathrm{CI})^{\star}\end{array}$} & \multirow[b]{2}{*}{$p$ value (Wald test) } \\
\hline & Intervention group & Control group & & \\
\hline $\begin{array}{l}\text { Score on foster carer report Strengths and } \\
\text { Difficulties Scale after training }\end{array}$ & $18(8)$ & $16(8)$ & $-0.8(-3.1,1.4)$ & 0.4 \\
\hline $\begin{array}{l}\text { Score on teacher report Strengths and Difficulties } \\
\text { Scale after training }\end{array}$ & $16(8)$ & $10(7)$ & $2(-3.0,7.0) \dagger$ & 0.4 \\
\hline $\begin{array}{l}\text { Score on child self report Strengths and Difficulties } \\
\text { Scale after training }\end{array}$ & $15(8)$ & $12(7)$ & $-2.1(-5.0,0.8) \dagger$ & 0.2 \\
\hline $\begin{array}{l}\text { Score on foster carer report Reactive Attachment } \\
\text { Disorder Scale after training }\end{array}$ & $21(9)$ & $18(9)$ & $-1.2(-3.5,1.1) \ddagger$ & 0.3 \\
\hline $\begin{array}{l}\text { Score on child self report Modified Rosenberg } \\
\text { Self-esteem Scale after training }\end{array}$ & $31(5)$ & $32(6)$ & $0.7(-2.3,3.7) \ddagger$ & 0.6 \\
\hline Median (range) cost of foster care after training & $£ 3792(2631,28713.5)$ & $£ 3271(10.5,16836.7)$ & $£ 1348(-407,3102)^{\star}$ & 0.1 \\
\hline
\end{tabular}

Values are means (SD) unless otherwise stated.

*Adjusted in ANCOVA for pretraining scores, the number of siblings in placement, and the age of the child.

tAdjusted in ANCOVA for pretraining scores, the number of children previously looked after by foster carers, the number of siblings in the placement, and the age and sex of the child.

$\ddagger$ Adjusted in ANCOVA for pretraining scores, the number of siblings in the placement, and the age and sex of the child. 
those only offered standard services. Carers invited to the training reported virtually no difference in the symptoms of attachment disorders immediately after the training.

OUTCOME NINE MONTHS AFTER TRAINING

Table 3 shows outcomes nine months posttraining. Again, we compared children whose families were invited to attend the extra training with those only offered standard services. Carers invited to the training reported non-significant improvements in attachment disorders and psychopathology. Teachers reported a non-significant worsening and children a non-significant improvement in psychopathology. Children also reported a nonsignificant improvement in self esteem. The costs of foster care in terms of service use increased non-significantly in the intervention group.

\section{Discussion}

Children in the sample had overwhelmingly suffered abuse and neglect, and over $60 \%$ had some degree of psychopathology. The trial showed that the training had measurable and possibly even clinically significant effects, but no statistically significant impact on child psychopathology or on costs, despite foster carers perceiving benefit to themselves and the children they were looking after.

The trial was designed to give a pragmatic evaluation of foster carer training within "mainstream" foster care. This is an under researched area, not least because of the layers of bureaucracy that have to be navigated in order to carry out research on these children, but calculations suggested that the study had sufficient power to detect meaningful changes in children's functioning. Our sample, however, had greater variability within it than the sample used for power calculation and, therefore, despite similar differences being found between intervention and control groups to those predicted, the results were not statistically significant. We achieved a heterogeneous sample similar to the wider population of foster families. ${ }^{1}$ The recruitment rate of $42 \%$ raises the possibility of unknown differences, but participants and non-participants were similar in deprivation category and placement breakdown rate, which makes major differences less likely.

There was greater attrition in the intervention group. More experienced carers, or those whose children have few problems, might have agreed to participate, hoping that they would not be randomised to training. The fact that the intervention group had looked after fewer children previously and their children had higher scores for psychopathology suggests this. Pretraining scores and the number of previous placements were entered into the regression analyses, which makes these factors less likely to cause bias.

The rate of attendance, while apparently low at $52 \%$, compared well with other training programmes, even those offering "catch up" sessions. ${ }^{33}$ Low attendance may be an intrinsic quality of foster carer training of this type.
The outcome measures may not have captured important differences between the groups. Also, differences between the intervention and control groups may increase with time, as noted in early intervention programmes for deprived children. ${ }^{34}$ This is particularly likely for the costs data. An increase in short term costs may be a result of families noticing more problems and instigating appropriate referral. Such short term increases in costs may turn into long term decreases as problems are dealt with.

The study set out to test the effects of a realistic intervention which could easily be adopted within current services and budgets. There is good evidence that, for children with severe psychopathology, "specialist" schemes are beneficial, ${ }^{8}$ but as is clear from this and other studies, more than half the children in "mainstream" foster care have significant mental health problems. Successful schemes offered two hour group sessions, three to five hours of face to face, plus frequent telephone contact with staff each week; therapy was given for child and family where appropriate, with a significantly improved fostering allowance. ${ }^{8} \mathrm{Re}-$ cently, researchers in the USA have suggested that we need to go beyond "specialist" foster care into "professional" foster care in which carers are paid a substantial annual salary in addition to good training and support. ${ }^{35}$ Our intervention was not sufficient to make a substantial impact on the children. Far more intensive interventions may now have to be considered.

\section{CONCLUSIONS}

Almost all children in a sample of those in foster care in Scotland had suffered abuse or neglect, and over $60 \%$ were suffering from measurable psychopathology. A training programme organised within existing services, despite being valued and perceived as beneficial by participants, did not impact on this massive level of psychopathology. Costly, intensive schemes for the most disturbed children in foster care have been shown to be effective. To institute such a radical reorganisation of services across the board would require a major effort of political will and a massive injection of finance, but may be what these children need. The cost must be offset against probable savings in later years. ${ }^{36}$ Such services require urgent evaluation.

We thank all participants, the Wellcome Trust for funding the study, and Alec McMahon, Kevin Pickering, and Morven Leese for statistical advice. Helen Minnis was principal investigator and was funded by a Wellcome Training Fellowship in Health and was funded by a Wellcome Training Fellowship in Health Service Research. She initiated the study, coordinated the trial,
preformed the statistical analysis, and prepared the first draft of preformed the statistical analysis, and prepared the first draft of
the paper. Judy Dunn helped to secure funding and, with the paper. Judy Dunn helped to secure funding and, with
Anthony Pelosi, supervised the study. Martin Knapp supervised the health economics aspect of the study and, with Helen Minnis, devised the Costs of Foster Care Questionnaire. All authors contributed to the final draft of the paper.

1 Triseliotis J, Borland M, Hill M. Fostering good relations: a study of foster care and foster carers in Scotland. Edinburgh: Scottish Office Central Research Unit, 1998.

2 Department of Health. Inspection of local authority fostering Department of Health. Inspection of local authority fostering

3 Utting W, Baines C, Stuart M, et al. People like us. London: Stationery Office, 1998. 
4 Triseliotis J, Sellick C, Short R. Foster care. Trowbridge, Wilts: Redwood, 1995

McCann JB, James A, Wilson S, Dunn G. Prevalence of psychiatric disorders in young people in the care system. BMҰ 1996;313:1529-30.

6 Dimigen G, Del Priore C, Butler S, et al. The need for a mental health service for children at commencement of being looked after and accommodated by the local authority: questionnaire survey. BMF 1999;319:675.

7 Hellinckx W, Grietens H. Prevalence of problem behavior in foster children in Flanders. Community Alternatives: International Fournal of Family Care 1994;6:27-46.

8 Chamberlain P, Moreland S, Reid K. Enhanced services and stipends for foster parents: effects on retention rates and outcomes for children. Child Welfare 1992;71:387-401.

9 Chamberlain P, Weinrott $M$. Specialized foster care: treating seriously emotionally disturbed children. Children Today 1990;19:24-7.

10 Clark HB, Prange ME, Lee B, et al. Improving adjustment outcomes for foster children with emotional and behavioral disorders: early findings from a controlled study on individualized services. Fournal of Emotional and Behavioral Disorders 1994;2:207-18.

11 Boyd LH, Remy LL. Is foster parent training worthwhile? Social Service Review 1978;52:275-96.

12 Guerney LF, Wolfgang G. Long-range evaluation of effects on foster parents of a foster parent skills training programme. $\mathcal{F}$ Clin Child Psychol 1981;10:33-7.

13 Hampson RB, Schulte MA, Ricks CC. Individual vs. group training for foster parents: efficiency/effectiveness evaluations. Family Relations 1983;32:191-201.

14 Crowell J, Feldman S. Mother's internal models of relationships and children's behavioural and developmental status: a study of mother-child interaction. Child Dev 1988;59: 1273-85.

15 Warren S, Huston L, Egeland B, Sroufe A. Child and adolescent anxiety disorders and early attachment. $f \mathrm{Am} \mathrm{Acad}$ Child Adolesc Psychiatry 1997;36:637-44.

16 Goldberg S. Recent developments in attachment theory and research. Can f Psychiatry 1991;36:393-400.

17 Reddy V, Hay D, Murray L, et al. Communication in infancy: mutual regulation of affect and attention In: Bremner G, Slater A, eds. Infant development: recent advances. Hove: Psychology Press/Erlbaum, 1997:247-73.

18 Klann-Delius G, Hofmeister C. The development of communicative competence of securely and insecurely attached children in interactions with their mothers. $\mathcal{F} P s y-$ cholinguist Res 1997;26:69-88.
19 Denham SA. Mother-child emotional communication and preschoolers' security of attachment and dependency. $\mathcal{F}$ Genet Psychol 1994;155:119-21.

20 McAuley C. Children in long-term foster care. Aldershot, UK: Avebury, 1996.

21 Kufeldt K, Armstrong J, Dorosh M. How children in care view their own and their foster families: a research study. Child Welfare 1995;74:695-715.

22 Gilligan R. The foster carer experience in Ireland: findings from a postal survey. Child Care Health Dev 1996;22:85-98.

23 Minnis H, Devine C, Pelosi A. Foster carers speak about training. Adoption and Fostering 1999;23.

24 Richman N. Communicating with children: helping children in distress. London: Save the Children, 1993.

25 Goodman R. The Strengths and Difficulties Questionnaire: a research note. F Child Psychol Psychiatry 1997;38:581-6.

26 Warr P, Jackson P. Factors influencing the psychological impact of prolonged unemployment and of reemployment. Psychol Med 1985;15:795-807.

27 Minnis H. Evaluation of a training programme for foster carers. London: University of London, 1999.

28 Netten A, Dennett J. Unit costs of health $\Xi$ social care, Vol. 5. Kent, UK: Personal Social Services Research Unit, 1997:1

29 Dunn J, Deater-Deckard K, Pickering K, O'Connor T. Children's adjustment and prosocial behaviour in step-, single-parent and non-stepfamily settings: findings from a single-parent and non-stepfamily settings: findings from a 95.

30 Ukoumunne OC, Gulliford MC, Chinn S, et al. Methods for evaluating area-wide and organisation-based interventions in health and health care: a systematic review. Health Technol Assess 1999;3.

31 Pocock SJ. Clinical trials, 12th ed. London: Wiley, 1983.

32 Huber PJ. The behaviour of maximum likelihood estimates under nonstandard conditions. In: Proceedings of the Fifth Berkeley Symposium on Mathematical Statistics and Probability, Vol. 1, 1967:221-33.

33 Hutchinson, B. Skills based training for foster carers. London: British Agents for Adoption and Fostering, 1997.

34 Weikart DP. Changing early childhood development through educational intervention. Prev Med 1998;27:2337.

35 Testa MF, Rolock N. Professional foster care: a future worth pursuing? Child Welfare 1999;78:108-24.

and interventions for children and adolescents with mental health problems. $f$ Child Psychol Psychiatry 1997;38:3-25. 